University of Nebraska - Lincoln

DigitalCommons@University of Nebraska - Lincoln

USDA National Wildlife Research Center - Staff Publications
U.S. Department of Agriculture: Animal and Plant Health Inspection Service

$12-18-2019$

\title{
A model for the prediction of antimicrobial resistance in Escherichia coli based on a comparative evaluation of fatty acid profiles
}

\author{
Randal S. Stahl \\ USDA/APHIS/WS,National Wildlife Research Center \& St. Jude Children's Research Hospital, \\ rstahl@rams.colostate.edu \\ Bledar Bisha \\ University of Wyoming \\ Sebabrata Mahapatra \\ Colorado State University \& St. Jude Children's Research Hospital \\ Jeffrey C. Chandler \\ USDA/APHIS/WS,National Wildlife Research Center \\ Follow this and additional works at: https://digitalcommons.unl.edu/icwdm_usdanwrc \\ Part of the Natural Resources and Conservation Commons, Natural Resources Management and \\ Policy Commons, Other Environmental Sciences Commons, Other Veterinary Medicine Commons, \\ Population Biology Commons, Terrestrial and Aquatic Ecology Commons, Veterinary Infectious Diseases \\ Commons, Veterinary Microbiology and Immunobiology Commons, Veterinary Preventive Medicine, \\ Epidemiology, and Public Health Commons, and the Zoology Commons
}

Stahl, Randal S.; Bisha, Bledar; Mahapatra, Sebabrata; and Chandler, Jeffrey C., "A model for the prediction of antimicrobial resistance in Escherichia coli based on a comparative evaluation of fatty acid profiles" (2019). USDA National Wildlife Research Center - Staff Publications. 2325.

https://digitalcommons.unl.edu/icwdm_usdanwrc/2325

This Article is brought to you for free and open access by the U.S. Department of Agriculture: Animal and Plant Health Inspection Service at DigitalCommons@University of Nebraska - Lincoln. It has been accepted for inclusion in USDA National Wildlife Research Center - Staff Publications by an authorized administrator of DigitalCommons@University of Nebraska - Lincoln. 


\title{
A model for the prediction of antimicrobial resistance in Escherichia coli based on a comparative evaluation of fatty acid profiles
}

\author{
Randal S. Stahl ${ }^{\mathrm{a}, *, 2}$, Bledar Bisha ${ }^{\mathrm{b}}$, Sebabrata Mahapatra ${ }^{\mathrm{c}, 1}$, Jeffrey C. Chandler ${ }^{\text {a }}$ \\ a USDA/APHIS/WS, National Wildlife Research Center, Fort Collins, CO, USA \\ ${ }^{\mathrm{b}}$ University of Wyoming, Department of Animal Science, Laramie, WY, USA \\ c Colorado State University, Department of Microbiology, Immunology, and Pathology, Fort Collins, CO, USA
}

\section{A R T I C L E I N F O}

\section{Article history:}

Received 16 July 2019

Received in revised form 31 October 2019

Accepted 6 December 2019

Available online 18 December 2019

\section{Keywords:}

Escherichia coli

GC-MS

Fatty acid

Antimicrobial susceptibility

\begin{abstract}
A B S T R A C T
Antimicrobial resistance is a threat to agricultural production and public health. In this proof-of-concept study, we investigated predicting antimicrobial sensitive/resistant $(\mathrm{S} / \mathrm{R})$ phenotypes and host sources of Escherichia coli $(n=$ 128 ) based on differential fatty acid abundance. Myristic (14:0), pentadecanoic acid (15:0), palmitic (16:0), elaidic $\left(18: 1^{9}\right)$ and steric acid $(18: 0)$ were significantly different $(\alpha=0.05)$ using a two-way ANOVA for predicting nalidixic acid, ciprofloxacin, aztreonam, cefatoxime, and ceftazidime S/R phenotypes. Additionally, analyses of palmitoleic (16:1), palmitic acid (16:0), methyl palmitate (i-17:0), and cis-9,10-methyleneoctadecanoic acid $\left(19: 0^{\Delta}\right)$ showed these markers were significantly different $(\alpha=0.05)$ between isolates obtained from cattle and raccoons. $S / R$ phenotype prediction for the above antibiotics or host source, based on linear regression models of fatty acid abundance, were made using a replicated-randomized subsampling and modeling approach. This model predicted S/R phenotype with $79 \%$ and $81 \%$ accuracy for nalidixic acid and ciprofloxacin, respectively. The isolate host source was predicted with $63 \%$ accuracy.
\end{abstract}

\section{Introduction}

The use and misuse of antibiotics in animal production, where an estimated 13.9 million $\mathrm{kg}$ of antimicrobials are used annually in the United States alone, is identified as a principle driver of antimicrobial resistance (AMR) throughout associated microbial ecosystems (Cully, 2014, U.S. FDA). Subsequently, AMR is disseminated through various pathways such as the food chain, wildlife interactions, and environmental factors (Davies and Davies, 2010; Robinson et al., 2016). Given that multiple classes of antimicrobials used in agricultural are also used in human medicine, and that global use of antimicrobials in livestock production is expect to increase, AMR in this sector represents a major public health risk (Van Boeckel et al., 2015). Accordingly, strategies are needed to simply and effectively classify antimicrobial susceptibility and facilitate source tracking of AMR inputs/outputs within agricultural production systems.

In Gram-negative bacteria, antibiotics generally must overcome the asymmetric permeability barriers of the outer and cytoplasmic membranes in order to reach their targets (Blair et al., 2015; Henderson et al., 2016; Schmidt et al., 2018; Wang et al., 2018). Antimicrobial movement

\footnotetext{
* Corresponding author. Tel.:1(970)430-5871; fax: 1(970)266-6063.

E-mail address: rstahl@rams.colostate.edu (R.S. Stahl).

1 current address: St. Jude Children's Research Hospital, Memphis, TN, USA.

2 Retired.
}

across the cell wall is typically governed by two main mechanisms, a diffusion pathway for hydrophobic compounds or the utilization of porins and selective channels for hydrophilic compounds (Blair et al., 2015; Bolhuis et al., 1997; Nikaido, 2003). Permeability of the cell wall is influenced by alterations in membrane fluidity, rigidity, curvature, and the activity of membrane proteins, properties partially determined by the composition and organization of the fatty acids contained within phospholipids and lipopolysaccharide (Bezrukov, 2000; Zhang and Rock, 2008). Thus, diversity and abundance of cell wall lipids and proteins are potentially diagnostic of antimicrobial susceptibility phenotypes (Blair et al., 2015; Henderson et al., 2016).

Differences in fatty acids including abundance, acyl chain length, extent of saturation, branching, and cycloproponation are recognized to alter antibiotic activity and permeability. For example, Escherichia coli and Klebsiella pneumoniae isolates resistant to tetracycline and polymyxin, respectively, were shown to have a relative increase in the abundance of unsaturated fatty acids and a decrease in cyclopropane fatty acids as compared to sensitive strains (Dunnick and O'Leary, 1970). Increased fatty acid saturation was correlated with nisin resistance in Clostridium botulinum isolates (Mazzotta and Montville, 1999). In Salmonella spp. isolates, increased acylation of lipid A conferred added resistance to cationic antimicrobial peptides (Guo et al., 1998). Pseudomonas aeruginosa isolates deficient in the LPS-specific fatty acid 2hydroxydodecanoic had increased susceptibility to $\beta$-lactam type antibiotics including third-generation cephalosporins (Six et al., 2014). 
Staphylococcus aureus isolates resistant to vancomycin and teicoplanin were shown to have increased relative abundance of saturated and iso/ anteiso branched fatty acids compared to sensitive cells (Goncalves and de Carvalho, 2016). Increased abundance of saturated fatty acids in S. aureus was also hypothesized to limit the pore-forming antimicrobial activity of daptomycin (Boudjemaa et al., 2018). Exogenous incorporation of linolenic acid, linoleic acid, and eicosapentaenoic acid was shown to increase susceptibility to polymyxin B in K. pneumonia isolates (Hobby et al., 2019).

Although bacterial fatty acid composition has recognized implications for antibiotic resistance, the utility of these features to allow for generalizable interpretation of antimicrobial susceptibility phenotypes is unclear. In this proof-of-concept study, a replicated-randomized subsampling and modeling approach was used to compare fatty acid abundance of wildtype Escherichia coli isolates with diverse antimicrobial susceptibilities. Specifically, isolates were obtained from the fecal material of cattle and raccoons from four farms in Colorado and were found to have resistances to antibiotics defined by the U.S. Centers for Disease Control and Prevention as urgent and serious threats, including resistance to fluoroquinolones and third-generation cephalosporins (U.S. CDC, 2013). Given exogenous uptake of fatty acids and differential host physiology, we tested the additional hypothesis that $E$. coli fatty acid profiles may be predicative of host source (cattle or raccoons).

Despite the myriad of non-fatty acid constituents and pathways related to antimicrobial susceptibility, our model which examined the differential abundance of just nine fatty acids allowed for prediction of quinolone susceptibility phenotypes in these E. coli isolates with approximately $80 \%$ accuracy. Statistically significant predictions were also possible for determining the host source as well as resistances to other antibiotics.

\section{Methods}

\subsection{Isolation of presumptive antimicrobial resistant E. coli from livestock production environments}

Wildlife and cattle fecal samples were collected on four livestock operations (denoted A - D) in Northern Colorado from 8/3/2012 to 9/7/ 2012. All studies were approved by the Institutional Animal Care and Use Committee at the National Wildlife Research Center. Upon receipt in the laboratory, $500 \mu \mathrm{L}$ of sterile saline solution was added to fecal samples collected in Whirl-Pak bags (Nasco, Ft. Atkinson, WI) and gently massaged for approximately $30 \mathrm{~s}$ and then stomached for 2 min in a Stomacher 400 Circulator (Seward Laboratory Systems Inc., Davie, FL). 6-inch sterile cotton-tipped applicators were inserted into the fecal homogenates and used to streak MacConkey Agar (Acumedia, Lansing, MI) supplemented with $1 \mu \mathrm{g} / \mathrm{mL}$ ciprofloxacin (CIP) (Enzo Life Sciences, Farmingdale, NY) or $2 \mu \mathrm{g} / \mathrm{mL}$ cefotaxime (CTX) (Calbiochem, EMD Millipore, Billerica, MA). Plates were incubated at $37^{\circ} \mathrm{C}$ for $24 \mathrm{~h}$. Colonies of distinctive morphology were picked and re-streaked for isolation on Tryptic Soy Agar (Becton-Dickinson, Franklin Lakes, NJ). Typical single colonies were subsequently transferred to $10 \mathrm{~mL}$ of Brain Heart Infusion Broth (BHI) (Becton-Dickinson), grown overnight at $37{ }^{\circ} \mathrm{C}$ for $18-24 \mathrm{~h}$ with shaking, mixed $1: 1$ with $40 \%$ sterile glycerol, and stored at $-80^{\circ} \mathrm{C}$ until further use.

\subsection{Confirmation of isolate identification by MALDI biotyping}

MALDI biotyping of the presumptive E. coli isolates was performed in accordance with established approaches (Mellmann et al., 2008). Briefly, one loopful (equivalent volume of $1 \mu \mathrm{L}$ ) of isolated bacteria (grown on the appropriate selective media described above) was suspended into $300 \mu \mathrm{L}$ of HPLC grade $\mathrm{H}_{2} \mathrm{O}$ (Millipore Sigma, Saint Louis, MO). To each suspension, $900 \mu \mathrm{L}$ of absolute ethanol (Millipore Sigma) was added, and precipitates were collected by centrifugation at $17,000 \times \mathrm{g}$. The ethanol-containing supernatant was removed, and the pellet air-dried for $5 \mathrm{~min}$. Pellets were suspended in a 1:1 ratio of $70 \%$ formic acid in $\mathrm{H}_{2} \mathrm{O}$ (Millipore Sigma) and acetonitrile (Millipore Sigma) to a volume of $180 \mu \mathrm{l}$. Insoluble material was removed by centrifugation at $17,000 \times \mathrm{g}$, and $1 \mu \mathrm{L}$ of each solution was applied to an MTP 384 polished steel T F target plate (Bruker, Billerica, MA). The sample was allowed to dry on the target plate until no liquid was visible before being overlaid with $1 \mu \mathrm{L}$ of freshly prepared $\alpha$-cyano-4hydroxycinnamic acid matrix (Bruker).

MALDI-TOF MS and was performed using the Bruker Ultraflex II TOF/TOF in positive ion reflector mode. The mass spectrometer was pre-calibrated with bacterial test standard (Bruker). MALDI biotyping was performed using the Bruker Biotyper software (Ver. 3.1.). Identifications were only accepted if scored $\geq 2.0$ by the Biotyper algorithm.

\subsection{Antimicrobial susceptibility testing}

Antimicrobial susceptibility testing of E. coli isolates was performed using the disk diffusion method in accordance with Clinical and Laboratory Standards Institute's (CLSI) Performance Standards for Antimicrobial Susceptibility Testing M100-S24. Specifically, Sensi-Discs (Becton-Dickinson) with the following antibiotics were used: gentamicin (GEN), tobramycin (TOB), amoxicillin-clavulanate (AMC), imipenem (IMP), cefazolin (CFZ), CTX, cefoxitin (FOX), ceftazidime (CAZ), CIP, sulfamethoxazole/trimethoprim (SXT), fosfomycin (FOS), aztreonam (AZA), nitrofurantoin (NIT), ampicillin (AMP), piperacillin (PIP), chloramphenicol (CAM), nalidixic acid (NAL), and tetracycline (TET). CLSI-established break points were used to qualify isolates as sensitive, intermediateresistant, or resistant to a particular antibiotic. Intermediate resistance was interpreted as resistant for all modeling analyses.

\subsection{Fatty acid extraction}

In preparation for fatty acid extraction, bacteria were propagated from glycerol stocks on tryptic soy agar (Becton-Dickinson) followed by incubation for $18 \mathrm{~h}$ at $37^{\circ} \mathrm{C}$. Bacteria were harvested and suspended in $0.5 \mathrm{~mL}$ of phosphate buffered saline, $\mathrm{pH} 7.4$, containing Pierce Protease Inhibitor Tablets (1 protease inhibitor tablet / $50 \mathrm{~mL})$, DNase $(30 \mu \mathrm{g} /$ $50 \mathrm{~mL}$ ), and (Millipore Sigma) and RNase (30 $\mathrm{g} / \mathrm{mL}$ ) (Millipore Sigma). Cells were then lysed by using 5 min of pulsed $(1 \mathrm{~s}$ on $/ 1 \mathrm{~s}$ off) probe sonication on ice using a FB120 probe sonicatior (Thermo Fisher) with an amplitude setting of 35 . All samples were stored at $-80^{\circ} \mathrm{C}$ until further use after an aliquot of the lysate was taken for protein quantitation. Protein concentration was determined by using the bicinchoninic acid assay (Smith et al., 1985).

The bacterial fatty acids were extracted using a modified Folch procedure and methyl esterified using $6 \mathrm{~N}$ methanolic $\mathrm{HCl}$ (Hamilton and Hamilton, 1992; Kiefer, 1997). An aliquot of $0.4 \mathrm{~mL}$ of the bacterial lysate suspension was brought to $0.5 \mathrm{~mL}$ with ultrapure $\mathrm{H}_{2} \mathrm{O}$. This suspension was extracted with $9.5 \mathrm{~mL}$ of a $2: 1(\mathrm{v} / \mathrm{v})$ chloroform $\left(\mathrm{CHCl}_{3}\right)$ / methanol $(\mathrm{MeOH})$ solution in a glass tube shaken for $10 \mathrm{~min}$ on an orbital shaker. The solution was then filtered through a $0.7 \mu \mathrm{m}$ glass frit filter. The filtered solution was washed with $2 \mathrm{~mL}$ of ultrapure $\mathrm{H}_{2} \mathrm{O}$ which was vacuum aspirated. This was followed by three successive washes using $1 \mathrm{~mL}$ of $\mathrm{CHCl}_{3} / \mathrm{MeOH} / \mathrm{H}_{2} \mathrm{O}$ prepared at 3:48:47 ( $\left.v / \mathrm{v}\right)$. Each wash solution (upper phase) was vacuum aspirated prior to the following wash step. The resulting bottom phase was dried under a stream of $\mathrm{N}_{2}$ at $55{ }^{\circ} \mathrm{C}$. The extract was then suspended in $1.95 \mathrm{~mL}$ of hexane to which $0.05 \mathrm{~mL}$ of a $1 \mathrm{mg} / \mathrm{mL}$ a methyl heneicosanoic acid (21:0) internal standard was added. The sample was then homogenized by bath sonication for $10 \mathrm{~min}$. A $1 \mathrm{~mL}$ aliquot of this solution was methyl esterified with $1 \mathrm{~mL}$ of $6 \mathrm{~N}$ methanolic $\mathrm{HCl}$ in a high-pressure reaction vessel heated to $65^{\circ} \mathrm{C}$ for $15 \mathrm{~min}$. The solution was washed with the addition of $1 \mathrm{~mL}$ of ultrapure $\mathrm{H}_{2} \mathrm{O}$. A $0.4 \mathrm{~mL}$ aliquot of the hexane layer was transferred to a tube and dried with $\mathrm{N}_{2}$ at $55{ }^{\circ} \mathrm{C}$. The resulting bacterial acid methyl esters (BAME) were suspended in $0.2 \mathrm{~mL}$ of hexane by bath sonicating for $10 \mathrm{~min}$. 


\subsection{Bacterial acid methyl ester analysis}

BAME were separated on an Agilent DB-5 ms column (Agilent, Santa Clara, CA), $20 \mathrm{~m} \times 0.18 \mathrm{~m}$ with a $0.18 \mu \mathrm{m}$ film following the injection of $1 \mu \mathrm{L}$ of the extract prepared above, using an Agilent 6890 gas chromatograph (GC) and detected by an Agilent 5973 mass spectrometer. The GC inlet was configured in split mode with an injection temperature of $300{ }^{\circ} \mathrm{C}$, using $\mathrm{He}$ as a carrier gas at a pressure of 22.8 psi with the spit ratio set at 20:1. Separation occurred under constant pressure with an average gas velocity of $30 \mathrm{~cm} / \mathrm{s}$. Compounds were eluted off the column using a thermal gradient. The GC oven was set at $150^{\circ} \mathrm{C}$ and held at this temperature for $2.5 \mathrm{~min}$. Temperature was increased at a rate of $7{ }^{\circ} \mathrm{C} / \mathrm{min}$ until the oven reached a final temperature of $250{ }^{\circ} \mathrm{C}$ and held at this temperature for $3 \mathrm{~min}$. The entire run time was $19.6 \mathrm{~min}$. The MS source was held at $230^{\circ} \mathrm{C}$ and the MS quadrupole at $150{ }^{\circ} \mathrm{C}$. The instrument scanned from $50 \mathrm{~m} / \mathrm{z}$ to $550 \mathrm{~m} / \mathrm{z}$ with a detection threshold set at an intensity of 150 ions. Retention time windows for BAME were established using a bacterial acid methyl ester mix (Supelco, 47,080-U). This mix contains 26 fatty acid methyl esters ranging from undecanoate methyl ester (11:0) to eicosanoate methyl ester (20:0). The standard was prepared by diluting $1 \mathrm{~mL}$ of the mix to $10.0 \mathrm{~mL}$ in hexane.

\subsection{GC-MS data analysis}

Peaks in the chromatograms were identified and integrated for total peak area using Agilent MSD Enhanced ChemStation software Ver. E02.02.1431. The peak areas in each chromatogram were corrected for peak area recovery for the internal standard and then normalized to the mass of protein determined in each sample. A two-way ANOVA was performed on the normalized peak areas observed for each bacterial fatty acid methyl ester determined for samples from the total population of isolates to evaluate whether the mean corrected peak areas for the isolate susceptible and resistant subpopulations are significantly different at the $\alpha=0.05$ level of significance. Additionally, a two-way ANOVA was performed on the corrected BAME peak areas to evaluate whether the difference in mean peak area is different by host. Bacterial acids identified as being significantly different $(\alpha=0.05$ ) by sensitive/ resistant $(\mathrm{S} / \mathrm{R})$ phenotype to an antibiotic or by the two hosts were used in linear regression classification models to predict the sample host source or S/R phenotype of an isolate (Varmuza and Filzmoser, 2009). The two-way ANOVA results for the determination of significance for BAME and the classifying variable (host or S/R for each antibiotic) were used to select the subset of classifying variables to identify the BAME to use to predict class membership. Linear regression for this subset was performed using all nine BAME to identify the significant BAME to be used in the prediction models.

Models developed for each classification variable from the BAME significant at $\alpha=0.05$ were evaluated for robustness by randomly subsampling 25 individuals from the combined cattle/raccoon population and using the remaining individuals to build a regression model which was used to predict the host for the remaining 25 samples and the prediction was compared to the actual host or S/R phenotype for accuracy. The prediction of the host for 25 samples was iterated 100 times. The subsample was limited to 25 samples to prevent the underrepresentation of the cattle or susceptible antibiotic test results samples in the construction of the regression class prediction model. All statistical analysis was performed using $\mathrm{R}$ (version 3.3.3).

\section{Results}

\subsection{Bacteria and AMR phenotypes}

In total, 392 E. coli isolates were collected from livestock production systems in Northern Colorado. All isolates were confirmed as E. coli using MALDI Biotyping. From these, a subset of 128 isolates was selected for BAME analyses on the basis of host source (cattle, $n=52$ or raccoons, $n=76$ ), sampling location, and the presence of high-priority antimicrobial susceptibility phenotypes, particularly resistances to quinolones and third-generation cephalosporins. Specifically, these bacteria were isolated from fecal samples $(n=921)$ using media supplemented with either a fluoroquinolone (CIP) or third-generation cephalosporin (CTX), thereby preferentially selecting isolates with these resistance phenotypes. To allow for a more generalizable prediction of AMR phenotypes through comparative BAME analyses, the isolates were also selected to represent a high diversity of AMR phenotypes and isolates were derived from four geographically distinct farms. Antimicrobial susceptibility testing (18 antibiotics tested) and the corresponding antibiograms demonstrated that the isolates selected comprised at least 73 phenotypically distinct groups of AMR E. coli (Table 1). Of the isolates selected for comparative fatty acid analyses, $73 \%, 70 \%, 38 \%, 59 \%$, and $54 \%$ were resistant to NAL, CIP, AZA, CTX, and CAZ, respectively.

\subsection{Analysis of BAMEs}

Chromatograms representative of E. coli BAMEs from the standard (bacterial acid methyl ester mix), cattle, and raccoon sample are presented in Supplemental Fig. 1. As expected, we consistently observed nine BAME across all the samples in this study. The retention times and mean corrected peak area (mean \pm 1 standard deviation) for each of the BAMEs, for all samples, is presented in Table 2. The compound identities were confirmed using both retention time windows compared to a standard and ion spectrum matches with the National Institute of Standards and Technology (Ver. 8.0) library. These bacterial fatty acid methyl esters included 14:0, pentadecanoate (15:0), 16:1, 16:0, 15methylpalmitate (i-17:0), margarate (17:0), elaidate $\left(18: 1^{9}\right), 18: 0$ and cis-9,10-methyleneoctadecanoate $\left(19: 0^{\Delta}\right)$. Elaidate is the confirmed octadecanoate-methyl ester present in the samples as demonstrated (see Supplemental Fig. 2) by the difference in retention time for the two isomers, oleate and elaidate with retention times of $12.5 \mathrm{~min}$ and $12.6 \mathrm{~min}$, respectively.

\subsection{Differential composition of BAMEs}

The two-way ANOVA results for the antibiotic S/R phenotype $x$ BAME evaluations revealed that for five antibiotics: CAZ, CTX, AZA, NAL, and CIP the mean peak area of a BAME was significantly different based on the $S / R$ phenotype. The statistical significance of the interaction between the $S / R$ phenotype and the nine BAMEs for these five antibiotics are presented as a calculated $\mathrm{F}$ statistic value and the probability of a greater F statistic in Table 3. Mean BAME peak areas were always statistically significantly different across all antibiotics evaluated. The peak areas associated with a given $S / R$ phenotype distribution for an antibiotic were never significant, independent of being associated with a specific BAME (data not shown). Similarly, the two-way ANOVA result for host $\times$ BAME on the magnitude of BAME peak areas was significantly different with the F statistic $=2.69$ and a probability of significance of a greater $\mathrm{F}$ being found $\mathrm{Pr}$. $=0.0062$.

The significance levels for the nine BAME as variables for regression models that predict class membership for host and the five antibiotic's $S / R$ phenotype are presented in Table 4. There was no BAME common to all the antibiotic models and the host model. However, one BAME, $18: 1^{9}$, is common to all the $S / R$ prediction models.

For the host classification or the antibiotic S/R classification models 25 samples were randomly subsampled their respective $S / R$ phenotype and host association were predicted from a model generated from the remaining data in the dataset, the mean of the peak area, and the standard deviation for the BAME used across the six predictor values (Table 5). Antimicrobial susceptibility phenotypes are host-independent in the models evaluated. For CTX, the BAME 14:0 mean peak area is $2585 \pm 1833$ for the "S" predictor class and $2704 \pm 1823$ for the "R" 
Table 1

Source and antibiograms of $E$. coli isolates.

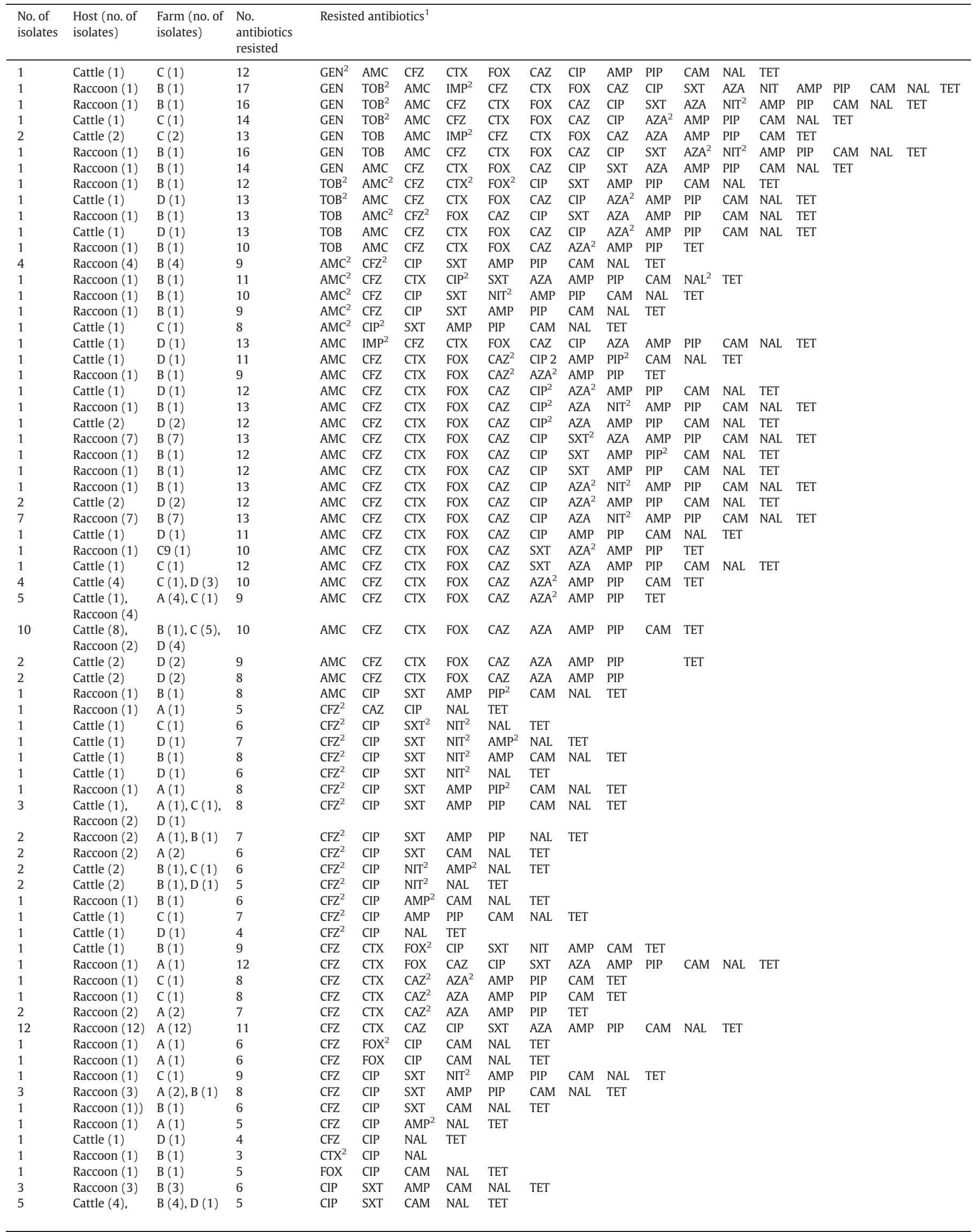


Table 1 (continued)

$\begin{array}{lllll}\begin{array}{l}\text { No. of } \\ \text { isolates }\end{array} & \begin{array}{l}\text { Host (no. of } \\ \text { isolates) }\end{array} & \begin{array}{l}\text { Farm (no. of } \\ \text { isolates) }\end{array} & \begin{array}{l}\text { No. } \\ \text { antibiotics } \\ \text { resisted }\end{array} & \text { Resisted antibiotics }^{1}\end{array}$

\begin{tabular}{|c|c|c|c|c|c|c|c|}
\hline & Raccoon (1) & & & & & & \\
\hline 1 & Raccoon (1) & $A(1)$ & 4 & CIP & SXT & NAL & TET \\
\hline 1 & Cattle (1) & $\mathrm{D}(1)$ & 4 & CIP & $\mathrm{NIT}^{2}$ & NAL & TET \\
\hline 1 & Raccoon (1) & $A(1)$ & 4 & CIP & CAM & NAL & TET \\
\hline 1 & Raccoon (1) & $\mathrm{B}(1)$ & 2 & CIP & NAL & & \\
\hline
\end{tabular}

1 AMC = amoxicillin-clavulanate; AMP = ampicillin; AZA = aztreonam; CAM = chloramphenicol; CAZ = ceftazidime; CFZ = cefazolin; CIP = ciprofloxacin; CTX = cefotaxme;

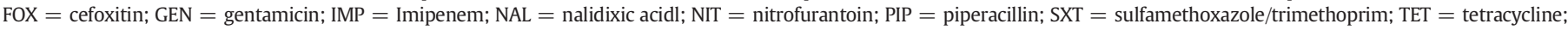
$\mathrm{TOB}=$ tobramycin.

${ }^{2}$ Indicates that the isolate phenotype had intermediate levels of antimicrobial resistance to the corresponding antibiotic.

predictor class. For the same BAME the mean peak area for cattle is $2972 \pm 1746$ and $2440 \pm 1823$ for raccoons. The probabilities of significance for $\mathrm{S} / \mathrm{R}$ and host prediction in Table 4 reflect the trends in Table 5 , where a BAME was significant when a smaller mean peak area for a $S / R$ phenotype also has a smaller standard deviation. For S/R phenotype prediction, peak area means are not likely to be statistically different when the magnitude of \pm 1 standard deviation are equal comparatively.

This process was replicated 100 times resulting in 2500 predictions for each antibiotic $S / R$ phenotype and the results of these predictions are presented in Table 6 . Across the five antibiotics the total percentage of correct predictions ranged from $53 \%$ to $81 \%$ based on BAME abundance. In all cases the models predict resistance much better than susceptibility to a given antibiotic. A similar analysis of the host source considering 2500 predictions resulted in a class prediction that 425 isolates were properly predicted to have originated from cattle. In total, this model correctly predicted that 1149 isolates originated from raccoon. The best predictive power of the model was for determining resistance phenotypes, with resistance correctly predicted for CTX, CAZ, AZA, NAL, and CIP with 80\%, 72\%, 76\%, 94\%, and 96\%, respectively.

601 isolates were improperly predicted to originate from raccoons when they actually originated in cattle and 325 isolates were improperly predicted to originate from raccoons. For the host prediction model, the total percentage of correct predictions across cattle and raccoon hosts is $63 \%$ and the ability to correctly predict raccoon as the host was $78 \%$ and the ability to correctly predict cattle as the host was only $41 \%$.

\section{Discussion}

In this proof-of-concept study, it was possible to draw statistically significant inferences from differential fatty acid abundance that allowed for the prediction of resistance in E. coli to CTX, CAZ, AZA, NAL, and CIP with $80 \%, 72 \%, 76 \%, 94 \%$, and $96 \%$, respectively. These predictions were based on the following five BAMEs: 14:0, 15:0, 16:0, 18:1 ${ }^{9}$ and 18:0. No more than three of these fatty acids were significant for predicting S/R phenotype for any single antibiotic and only one $18: 1^{9}$ was significant for all five antibiotics. Generally, new antimicrobial

Table 2

Bacterial acid methyl ester normalized mean peak area and retention times for chromatograms.

\begin{tabular}{llll}
\hline Fatty acid & Notation & $\begin{array}{l}\text { Retention } \\
\text { time }(\mathrm{min})\end{array}$ & $\begin{array}{l}\text { Corrected mean peak } \\
\text { area }(\mathrm{mz} \pm 1 \mathrm{sd})\end{array}$ \\
\hline Myristic acid & $14: 0$ & 7.1 & $2656 \pm 1821$ \\
Pentadecanoate & $15: 0$ & 8.5 & $2431 \pm 1586$ \\
Palmitoleic acid & $16: 1$ & 9.7 & $24,433 \pm 9046$ \\
Palmitic acid & $16: 0$ & 10 & $86,081 \pm 22,812$ \\
Methyl palmitate & $\mathrm{i}-17: 0$ & 11.2 & $37,447 \pm 11,327$ \\
Heptadecanoate & $17: 0$ & 11.5 & $2137 \pm 1032$ \\
Elaidic acid & $18: 1^{9}$ & 12.6 & $44,091 \pm 13,837$ \\
Steric acid & $18: 0$ & 12.8 & $23,697 \pm 10,587$ \\
Cis-9,10-methyleneoctadecanoate & $19: 0^{\Delta}$ & 14 & $6343 \pm 2960$ \\
\hline
\end{tabular}

susceptibility testing methods for commercial application should have 90\% essential agreement with the comparative reference method (Humphries et al., 2018), suggesting that profiling fatty acids may be a viable tool for determining antimicrobial susceptibility in E. coli, particularly for quinolone and fluoroquinolone resistance.

The primary targets of NAL and CIP are the cytoplasmic enzymes DNA gyrase and topoisomerase IV. Therefore, these antibiotics must cross the Gram-negative cell wall to be effective. Permeability-related resistance of NAL and CIP is associated with the reduced expression of outer membrane porin diffusion channels and basal or increased expression of antibiotic efflux pumps (Aldred et al., 2014; Hooper and Jacoby, 2015). Additionally, both of these antibiotics have small polar surface areas which facilitates their passive diffusion through the cytoplasmic membrane (Cramariuc et al., 2012). In contrast, $\beta$-lactam type antibiotics (including CAZ, CTX, AZA) target penicillin binding proteins which are typically localized to the cell wall. $\beta$-lactams are hydrophilic, and generally reach their target by passage through outer membrane porins through a process which is non-specifically mediated by the physicochemical properties of the molecule including charge, size, and hydrophobicity (Kojima and Nikaido, 2013). Thus, although the targets of the quinolones, fluoroquinolones, and $\beta$-lactams are not directly related to fatty acid metabolism, it is clear that fatty acids can contribute to the resistance of these antibiotics through alteration of membrane permeability.

When evaluating how the trends in the concentrations of these BAME changed in association with the $\mathrm{S} / \mathrm{R}$ phenotype of the $E$. coli isolates, for all five antibiotics (CIP, NAL, CAZ, CTX, and AZA), the mean quantity of the $18: 1^{9}$ (trans isomer) was higher in the R phenotype compared to the $S$ phenotype (see Table 5). This likely decreases the permeability of the bacterial cell wall given that isomerization of cis unsaturated fatty acids to the trans isomer are recognized to decrease membrane fluidity (Keweloh and Heipieper, 1996). In evaluating the abundance of unsaturated fatty acids in prediction of susceptibility phenotypes, for both NAL and CIP the mean concentration of 16:0 was higher in the $S$ phenotype compared to the R phenotype. For CAZ and AZA, the mean concentration of 18:0 was higher in the $S$ phenotype compared to the $\mathrm{R}$ phenotype. It is recognized that high levels of saturated fatty acids decrease membrane fluidity, and slightly decreased fluidity in E. coli was apparent upon exposure of subinhibitory concentrations of CIP and CAZ (Bessa et al., 2018; Zhang and Rock, 2008). Inconsistent with this

Table 3

Two-way ANOVA evaluation of significance for BAME, the AMR S/R class or host source as a predictor variable.

\begin{tabular}{lll}
\hline Antibiotic & F statistic & Probablity of a larger F value \\
\hline CTX & 3.55 & 0.00045 \\
CAZ & 2.3 & 0.019 \\
AZA & 2.39 & 0.015 \\
NAL & 2.69 & 0.0062 \\
CIP & 4.36 & 0.0000341 \\
\hline
\end{tabular}

The statistical significance of the interaction of $S / R$ phenotype $\times$ BAME on magnitude of a BAME peak area for CTX, CAZ, AZA, NAL, and CIP. All values are significant at $\alpha=0.05$. 
Table 4

Linear regression model evaluation of BAME significance in predicting class membership for $\mathrm{S} / \mathrm{R}$ class or host source.

\begin{tabular}{lllllll}
\hline \multirow{7}{*}{ Notation } & \multicolumn{7}{l}{ Significance $(\alpha)$ of predictor class ${ }^{1}$} \\
\cline { 2 - 7 } & CTX & CAZ & AZA & NAL & CIP & Host \\
\hline $14: 0$ & 0.074 & 0.11 & 0.078 & $\underline{0.009}$ & $\underline{0.0094}$ & 0.064 \\
$15: 0$ & 0.11 & 0.12 & $\underline{0.048}$ & $\overline{0.45}$ & 0.46 & 0.058 \\
$16: 1$ & 0.41 & 0.44 & 0.23 & 0.35 & 0.62 & 0.00019 \\
$16: 0$ & $\underline{0.017}$ & 0.071 & 0.1 & $\underline{0.035}$ & $\underline{0.027}$ & $\underline{0.0045}$ \\
$\mathrm{i}-17: 0$ & 0.43 & 0.54 & 0.55 & 0.66 & 0.87 & $\underline{0.0086}$ \\
$17: 0$ & 0.051 & 0.053 & 0.084 & 0.33 & 0.31 & 0.91 \\
$18: 1^{9}$ & 0.0016 & $\underline{0.012}$ & $\underline{0.014}$ & $\underline{0.00025}$ & $\underline{0.00079}$ & 0.43 \\
$18: 0$ & 0.065 & $\underline{0.046}$ & $\underline{0.032}$ & 0.19 & 0.23 & 0.43 \\
$19: 0^{\Delta}$ & 0.98 & 0.85 & 0.57 & 0.13 & 0.2 & $\underline{0.0008}$ \\
\hline
\end{tabular}

${ }^{1}$ BAME that are significant at $\alpha=0.05$ for class prediction for each predictor variable are underlined.

expectation, in this study the $\mathrm{S}$ phenotype had a lower mean concentration of 16:0 than the R phenotypes for CTX.

In this work, changes in fatty acid composition could have been related to environmental stressors and host-specific factors, such as exogenous uptake. Here, fatty acid composition was potentially biased by three main factors. First, the initial culture isolation methods utilized two different antibiotics for selection (CTX and CIP). Secondly, the gut environment in raccoons (monogastric) vs. cattle (ruminants) represents very different environmental stressors which could impact fatty acid composition (Cummings et al., 1995). Finally, in preparation for BAME analyses, all isolates were propagated identically using BHI and TSA, potentially normalizing the aforementioned stress responses.

For host prediction, 16:0 was slightly more abundant in raccoons compared to cattle, and while this fatty acid would be expected to decrease overall membrane fluidity, the difference is small and offset by a larger increase in the mean concentration of the 16:1 also observed in raccoons, which has the expected offsetting effect of increasing membrane fluidity. The mean concentration of the BAME i-17:0 was greater in isolates obtained from cattle than those from raccoons. Incorporation of branched chain fatty acids into the membrane can increase fluidity if the branch chain is iso-configured, as found in the cattle isolates, and will decrease fluidity if the branched chain is anteiso-configured, as found in the raccoon isolates, and this mechanism is commonly used in Gram-positive bacteria to modify membrane fluidity (Zhang and Rock, 2008). Boudjeema et al. reported that $S$. aureus decreased both iso and anteiso-branched chain fatty acids while increasing saturated fatty acids in the membrane in response to daptomyacin exposure (Boudjemaa et al., 2018).
Table 6

Class prediction results based on the BAME determined to be significant at $\alpha=0.05$ using a linear regression model.

\begin{tabular}{|c|c|c|c|c|c|}
\hline Classification & CTX & CAZ & AZA & NAL & CIP \\
\hline \multicolumn{6}{|c|}{ Number predicted correctly by S/R phenotype } \\
\hline $\mathrm{S}$ as $\mathrm{S}$ & 273 & 325 & 289 & 230 & 262 \\
\hline $\mathrm{R}$ as $\mathrm{R}$ & 1221 & 1049 & 1036 & 1749 & 1773 \\
\hline \multicolumn{6}{|c|}{ Number predicted incorrectly by S/R phenotype } \\
\hline $\mathrm{S}$ as $\mathrm{R}$ & 706 & 710 & 843 & 417 & 382 \\
\hline $\mathrm{R}$ as $\mathrm{S}$ & 300 & 416 & 332 & 104 & 83 \\
\hline \multicolumn{6}{|c|}{ Percentages of total count $(n=2500)$ by class $(\%)$} \\
\hline Total correct both classes & 60 & 55 & 53 & 79 & 81 \\
\hline Total correct for S or cattle & 28 & 31 & 26 & 36 & 41 \\
\hline Total correct for $\mathrm{R}$ or raccoon & 80 & 72 & 76 & 94 & 96 \\
\hline
\end{tabular}

The other BAME significant for host prediction was 19:0 $0^{\triangle}$, which as a cyclopropane has been reported to effect membrane fluidity in response to a number of environmental factors in $E$. coli. Cyclopropane fatty acids increase membrane fluidity while increasing membrane stability under a variety of stressors including exposure to changing temperatures, acids, ethanol, osmotic stress, and low pH (Chen and Ganzle, 2016; Zhang and Rock, 2008). Cyclopropane fatty acid modifications to membrane phospholipids have been observed to occur during early stationary phase and occurs as a result of the addition of a methylene group from s-adenosyl-methionine to a cis-double bond of an unsaturated fatty acid (Huang et al., 2002; Wang and Cronan Jr, 1994). Changes in the abundance of cyclopropane fatty acids are also reported in response to antibiotic exposure. Dunnick and O'Leary reported that multiple strains of tetracycline-resistant $E$. coli had decreased cyclopropane fatty acids, and increased concentrations of unsaturated fatty acids, as compared with sensitive strains (Dunnick and O'Leary, 1970). Schmidt et al. reported decreased susceptibility in E. coli to the antimicrobial peptide apidaecin 1 when levels of cyclopropane-modified fatty acids were decreased in cell membranes (Schmidt et al., 2018). Wang et al. reported that $E$. coli increased membrane fluidity by increasing unsaturated fatty acid content relative to cyclopropane and saturated fatty acids after exposure to naringenin, a bioactive flavonoid (Wang et al., 2018). In contrast, S. aureus exposed to naingenin increased anteiso-branched chain fatty acids while iso-branched fatty acids and straight chain fatty acids decreased (Wang et al., 2018).

Fatty acids impact trans-membrane proteins directly by interacting with the protein and collectively by impacting fluidity, bilayer thickness, and shape which can influence protein conformation and function (Vance and Vance, 2008; White et al., 2001). Interactions of the various changes in membrane fatty acid composition may be

Table 5

BAME $\mathrm{m} / \mathrm{z}$ mean peak area and standard deviation for the five antibiotic predictor classes and host that were significant in the two-way ANOVA.

\begin{tabular}{|c|c|c|c|c|c|c|c|}
\hline Notation & Class & CTX & CAZ & AZA & NAL & CIP & Host \\
\hline \multirow[t]{2}{*}{ 14:0 } & S/cattle & $2585 \pm 1833$ & $2677 \pm 1834$ & $2734 \pm 1852$ & $2532 \pm 1974$ & $2542 \pm 1970$ & $2972 \pm 1746$ \\
\hline & $\mathrm{R} /$ raccoon & $2704 \pm 1823$ & $2642 \pm 1824$ & $2592 \pm 1805$ & $2699 \pm 1773$ & $2696 \pm 1775$ & $2440 \pm 1850$ \\
\hline \multirow[t]{2}{*}{$15: 0$} & S/cattle & $2344 \pm 1957$ & $2370 \pm 1971$ & $2515 \pm 2027$ & $2370 \pm 1341$ & $2392 \pm 1343$ & $2308 \pm 1093$ \\
\hline & $\mathrm{R} /$ raccoon & $2489 \pm 1294$ & $2474 \pm 1315$ & $2362 \pm 1107$ & $2452 \pm 1669$ & $2445 \pm 1668$ & $2516 \pm 1852$ \\
\hline \multirow[t]{2}{*}{$16: 1$} & S/cattle & $22,928 \pm 8901$ & $23,386 \pm 8875$ & $23,378 \pm 8504$ & $22,213 \pm 9445$ & $22,441 \pm 9658$ & $22,040 \pm 6910$ \\
\hline & $\mathrm{R} /$ raccoon & $25,429 \pm 9060$ & $25,172 \pm 9150$ & $25,307 \pm 9442$ & $25,204 \pm 8823$ & $25,124 \pm 8770$ & $26,070 \pm 9970$ \\
\hline \multirow[t]{2}{*}{$16: 0$} & S/cattle & $79,530 \pm 24,075$ & $81,275 \pm 24,275$ & $81,757 \pm 24,032$ & $89,375 \pm 23,345$ & $91,675 \pm 26,789$ & $86,033 \pm 20,102$ \\
\hline & $\mathrm{R} /$ raccoon & $90,420 \pm 20,986$ & $89,476 \pm 21,232$ & $89,663 \pm 21,260$ & $84,936 \pm 22,636$ & $84,138 \pm 21,070$ & $86,113 \pm 24,625$ \\
\hline \multirow[t]{2}{*}{$\mathrm{i}-17: 0$} & S/cattle & $34,153 \pm 11,404$ & $34,707 \pm 11,202$ & $34,961 \pm 11,206$ & $42,955 \pm 9681$ & $44,400 \pm 12,398$ & $40,417 \pm 11,884$ \\
\hline & $\mathrm{R} /$ raccoon & $39,629 \pm 10,805$ & $39,384 \pm 11,084$ & $39,507 \pm 11,088$ & $35,534 \pm 11,274$ & $35,032 \pm 9908$ & $35,416 \pm 10,533$ \\
\hline \multirow[t]{2}{*}{$17: 0$} & S/cattle & $1965 \pm 1055$ & $1982 \pm 1041$ & $2068 \pm 1115$ & 2015v946 & $2064 \pm 974$ & $2028 \pm 964$ \\
\hline & $\mathrm{R} /$ raccoon & $2250 \pm 1007$ & $2246 \pm 1018$ & $2194 \pm 962$ & $2179 \pm 1061$ & $2162 \pm 1055$ & $2212 \pm 1076$ \\
\hline \multirow[t]{2}{*}{$18: 1^{9}$} & S/cattle & $42,565 \pm 14,075$ & $42,897 \pm 13,944$ & $42,783 \pm 13,391$ & $40,320 \pm 14,015$ & $41,358 \pm 15,599$ & $40,737 \pm 11,089$ \\
\hline & $\mathrm{R} /$ raccoon & $45,103 \pm 13,676$ & $44,936 \pm 13,792$ & $45,175 \pm 14,200$ & $45,402 \pm 13,605$ & $45,042 \pm 13,127$ & $46,388 \pm 15,082$ \\
\hline \multirow[t]{2}{*}{$18: 0$} & S/cattle & $23,667 \pm 11,944$ & $24,384 \pm 12,208$ & $24,630 \pm 12,338$ & $21,650 \pm 10,185$ & $22,282 \pm 10,372$ & $21,766 \pm 7253$ \\
\hline & $\mathrm{R} /$ raccoon & $23,718 \pm 9667$ & $23,212 \pm 9332$ & $22,924 \pm 8901$ & $24,408 \pm 10,684$ & $24,189 \pm 10,671$ & $25,019 \pm 12,234$ \\
\hline \multirow[t]{2}{*}{$19: 0^{\Delta}$} & S/cattle & $5945 \pm 2909$ & $5960 \pm 2860$ & $5985 \pm 2797$ & $7893 \pm 2893$ & $8108 \pm 3044$ & $7004 \pm 2892$ \\
\hline & $\mathrm{R} /$ raccoon & $6607 \pm 2983$ & $6615 \pm 3018$ & $6640 \pm 3076$ & $5830 \pm 2820$ & $5731 \pm 2685$ & $5892 \pm 2939$ \\
\hline
\end{tabular}

The values in the bold type face correspond to the BAME identified as significantly different for an antibiotic or host as presented in Table 4 . 
difficult to interpret, and relatively little is known regarding these interactions on antimicrobial susceptibility (Bezrukov, 2000; Vance and Vance, 2008). Nonetheless, average fatty acid composition has been shown better predict membrane transport rates as compared to phospholipid composition, which could be particularly important in interpreting the results observed in this study in which predictions of antibiotic resistance were possible for small polar compounds (Overath et al., 1971). For example, embedded membrane proteins are sensitive to the curvature in the membrane as well as the chemical composition of the lipid bilayer and that transfer rates of substrate are dependent on both (Cronan and Vagelos, 1972; Vance and Vance, 2008). In certain bacterial outer membrane proteins, $\beta$-barrel porins are ordered by adjacent acyl chains present on lipopolysaccharide via van der Waals interactions. Additionally, many membrane proteins exist as complexes and acyl chains in the membrane bilayer provide conformational flexibility between these subunits. Many trans-membrane proteins have a $20-25$ amino acid $\alpha$-helix that spans the 30 - $\AA$ bilayer and specific acyl fatty acid groups are often required by proteins for normal function.

\section{Conclusions}

It has long been recognized that changes in bacterial fatty acid composition reflect differences in antimicrobial susceptibility phenotype. However, these observations are typically based upon individual isolates or small subsets of isolates. Here we apply a replicatedrandomized subsampling and modeling approach to draw generalizable inferences on antimicrobial susceptibility (based upon fatty acid composition) in a population of $128 \mathrm{E}$. coli isolates. Although the physiology underlying antibiotic susceptibility is complex, this model allowed us to predict quinolone resistance with $90 \%$ accuracy, using just three fatty acids. Statistically significant predictions of third-generation cephalosporin (72-80\% accuracy) and monobactam (76\% accuracy) resistance were also possible.

Supplementary data to this article can be found online at https:// doi.org/10.1016/j.diagmicrobio.2019.114966.

\section{Acknowledgements}

This research was supported by the U.S. Department of Agriculture/Animal Plant Health Inspection Service/Wildlife Services project QA-2558, and Wyoming Agricultural Experiment Station project WYO-511-14.

\section{References}

Aldred KJ, Kerns RJ, Osheroff N. Mechanism of quinolone action and resistance. Biochemistry 2014;53(10):1565-74.

Bessa LJ, Ferreira M, Gameiro P. Evaluation of membrane fluidity of multidrug-resistant isolates of Escherichia coli and Staphylococcus aureus in presence and absence of antibiotics. J Photochem Photobiol B 2018;181:150-6.

Bezrukov SM. Functional consequences of lipid packing stress. Curr Opin Colloid Interface Sci 2000:5(3):237-43.

Blair JM, Webber MA, Baylay AJ, Ogbolu DO, Piddock LJ. Molecular mechanisms of antibiotic resistance. Nat Rev Microbiol 2015;13(1):42-51.

Bolhuis H, van Veen HW, Poolman B, Driessen AJ, Konings WN. Mechanisms of multidrug transporters. FEMS Microbiol Rev 1997;21(1):55-84.

Boudjemaa R, Cabriel C, Dubois-Brissonnet F, Bourg N, Dupuis G, Gruss A, et al. Impact of bacterial membrane fatty acid composition on the failure of Daptomycin to kill Staphylococcus aureus. Antimicrob Agents Chemother 2018;62(7).

Chen YY, Ganzle MG. Influence of cyclopropane fatty acids on heat, high pressure, acid and oxidative resistance in Escherichia coli. Int J Food Microbiol 2016;222:16-22.

Cramariuc O, Rog T, Javanainen M, Monticelli L, Polishchuk AV, Vattulainen I. Mechanism for translocation of fluoroquinolones across lipid membranes. Biochim Biophys Acta 2012;1818(11):2563-71.
Cronan JE, Vagelos PR. Metabolism and function of the membrane phospholipids of Escherichia coli. Biochim Biophys Acta 1972;265(1):25-60.

Cully M. Public health: the politics of antibiotics. Nature 2014;509(7498):S16-7

Cummings JH, Rombeau JL, Sakata T. Physiological and clinical aspects of short-chain fatty acids. New York, NY: Cambridge University Press, 1995. xx, 575 p. p.

Davies J, Davies D. Origins and evolution of antibiotic resistance. Microbiol Mol Biol Rev 2010;74(3):417-33

Dunnick JK, O'Leary WM. Correlation of bacteria lipid composition with antibiotic resistance. J Bacteriol 1970;101(3):892-900.

Goncalves FD, de Carvalho CC. Phenotypic modifications in Staphylococcus aureus cells exposed to high concentrations of vancomycin and teicoplanin. Front Microbiol 2016;7:13.

Guo L, Lim KB, Poduje CM, Daniel M, Gunn JS, Hackett M, et al. Lipid a acylation and bacterial resistance against vertebrate antimicrobial peptides. Cell 1998;95(2):189-98.

Hamilton RJ, Hamilton S. Lipid analysis: a practical approach. Oxford ; New York: IRL Press at Oxford University Press, 1992. xviii, 310 p. p.

Henderson JC, Zimmerman SM, Crofts AA, Boll JM, Kuhns LG, Herrera CM, et al. The power of asymmetry: architecture and assembly of the gram-negative outer membrane lipid bilayer. Annu Rev Microbiol 2016;70:255-78.

Hobby CR, Herndon JL, Morrow CA, Peters RE, Symes SJK, Giles DK. Exogenous fatty acids alter phospholipid composition, membrane permeability, capacity for biofilm formation, and antimicrobial peptide susceptibility in Klebsiella pneumoniae. Microbiology 2019;8(2), e00635

Hooper DC, Jacoby GA. Mechanisms of drug resistance: quinolone resistance. Ann N Y Acad Sci 2015;1354:12-31.

Huang CC, Smith CV, Glickman MS, Jacobs Jr WR, Sacchettini JC. Crystal structures of mycolic acid cyclopropane synthases from Mycobacterium tuberculosis. J Biol Chem 2002;277(13):11559-69.

Humphries RM, Ambler J, Mitchell SL, Castanheira M, Dingle T, Hindler JA, et al. CLSI methods development and standardization working group best practices for evaluation of antimicrobial susceptibility tests. J Clin Microbiol 2018;56(4).

Keweloh H, Heipieper HJ. Trans unsaturated fatty acids in bacteria. Lipids 1996;31(2): 129-37.

Kiefer K. Derivatization of corn oil for analysis by GC. Supelco Application Note 123 1997; 16(3):6

Kojima S, Nikaido H. Permeation rates of penicillins indicate that Escherichia coli porins function principally as nonspecific channels. Proc Natl Acad Sci U S A 2013;110 (28):E2629-34

Mazzotta AS, Montville TJ. Characterization of fatty acid composition, spore germination, and thermal resistance in a nisin-resistant mutant of Clostridium botulinum 169B and in the wild-type strain. Appl Environ Microbiol 1999;65(2):659-64.

Mellmann A, Cloud J, Maier T, Keckevoet U, Ramminger I, Iwen P, et al. Evaluation of matrix-assisted laser desorption ionization-time-of-flight mass spectrometry in comparison to $16 \mathrm{~S}$ rRNA gene sequencing for species identification of nonfermenting bacteria. J Clin Microbiol 2008;46(6):1946-54

Nikaido H. Molecular basis of bacterial outer membrane permeability revisited. Microbiol Mol Biol Rev 2003;67(4):593-656.

Overath P. Hill FF, Lamnek-Hirsch I. Biogenesis of E. coli membrane: evidence for randomization of lipid phase. Nat New Biol 1971;234(52):264-7.

Robinson TP, Bu DP, Carrique-Mas J, Fevre EM, Gilbert M, Grace D, et al. Antibiotic resistance is the quintessential one health issue. Trans R Soc Trop Med Hyg 2016;110 (7):377-80.

Schmidt R, Yonghong D, Hoffmann R. Phospholipid composition of the outer membrane of Escherichia coli influences its susceptibility against antimicrobial peptide apidaecin 1b. Diagn Microbiol Infect Dis 2018;90(4):316-23.

Six DA, Yuan Y, Leeds JA, Meredith TC. Deletion of the beta-acetoacetyl synthase FabY in Pseudomonas aeruginosa induces hypoacylation of lipopolysaccharide and increases antimicrobial susceptibility. Antimicrob Agents Chemother 2014;58(1):153-61.

Smith PK, Krohn RI, Hermanson GT, Mallia AK, Gartner FH, Provenzano MD, et al. Measurement of protein using bicinchoninic acid. Anal Biochem 1985;150(1):76-85.

United States Centers for Disease Control and Prevention. Antibiotic resistance threats in the United States, 2013.

Van Boeckel TP, Brower C, Gilbert M, Grenfell BT, Levin SA, Robinson TP, et al. Global trends in antimicrobial use in food animals. Proc Natl Acad Sci U S A 2015;112 (18):5649-54

Vance DE, Vance JE. Biochemistry of lipids, lipoproteins and membranes. 5th ed. Amsterdam; Boston: Elsevier, 2008. xii, 631 p., 8 p.

Varmuza K, Filzmoser P. Introduction to multivariate statistical analysis in chemometrics. Boca Raton: CRC Press, 2009. xiii, 321 p. p.

Wang AY, Cronan Jr JE. The growth phase-dependent synthesis of cyclopropane fatty acids in Escherichia coli is the result of an RpoS(KatF)-dependent promoter plus enzyme instability. Mol Microbiol 1994;11(6):1009-17.

Wang LH, Zeng XA, Wang MS, Brennan CS, Gong D. Modification of membrane properties and fatty acids biosynthesis-related genes in Escherichia coli and Staphylococcus aureus: implications for the antibacterial mechanism of naringenin. Biochim Biophys Acta Biomembr 2018;1860(2):481-90.

White $\mathrm{SH}$, Ladokhin AS, Jayasinghe S, Hristova K. How membranes shape protein structure. J Biol Chem 2001;276(35):32395-8.

Zhang YM, Rock CO. Membrane lipid homeostasis in bacteria. Nat Rev Microbiol 2008;6 (3):222-33. 